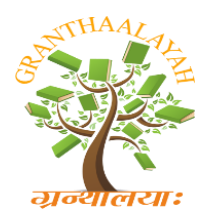

INTERNATIONAL JOURNAL OF RESEARCH GRANTHAALAYAH

A knowledge Repository

Management

\title{
WORK FROM HOME- A SUCCESS OR FAILURE IN DEVELOPING COUNTRY LIKE INDIA
}

\author{
Shweta Goel ${ }^{* 1}$, Monika ${ }^{2}$ \\ ${ }^{* 1}$ Mcom (NET), Delhi University, INDIA \\ ${ }^{2}$ Mcom (NET, JRF), Delhi University, INDIA
}

\begin{abstract}
Work carried out by an individual in his or her home or any other place of his/her choice is called work from home. This paper presents an overview of work from home concept and explains its necessity in today's time. This paper focus on recent status of WFH in India and challenges faced by it in its implementation.
\end{abstract}

Keywords:

Efficiency, performance, comfortable life, output, WFH.

Cite This Article: Shweta Goel, and Monika, "WORK FROM HOME- A SUCCESS OR FAILURE IN DEVELOPING COUNTRY LIKE INDIA" International Journal of Research Granthaalayah, Vol. 4, No. 3 (2016): 176-181.

\section{INTRODUCTION}

A rising number of employees now- a- days want to work from home but there are some issues which lead to 'shirking from home. The use of term 'informal employment' is not recent as it dates back to 1970s; however a clear definition of work from home is more recent.

In south Asia the concept of WFH evolved from home based craft production. Employees or workers especially females find it easy to work from home by combining care and responsibilities with less pressure on family and community norms. Working from home not only increases the productivity of employees which in turn increases the output per worker but also reduces the cost of the company in terms of space, infrastructure etc. Employees feel more satisfied and comfortable working at home.

A study in China shows that by switching from work from office to home has lead to $13 \%$ increase in productivity of workers. We know that every coin has two sides; similarly this concept also has certain limitations. It cannot be applied everywhere in all types of business and all types of firms. There are certain companies where work needs to be done from office premises only or where direct public dealing is required. In this paper we will analyze the impact 
of work from home in different types of companies and to what extent it is applicable in developing country like India.

As per Convention No 177 of the ILO (1996), work from home means

a) "work carried out by a person, to be referred to as a home worker, - in his or her home or in other premises of his or her choice, other than the workplace of the employer;

b) for remuneration;

c) which results in a product or service as specified by the employer, irrespective of who provides the equipment, materials or other inputs used, as long as this person does not have the degree of autonomy and of economic independence necessary to be considered an independent worker under national laws, regulations or court decisions;

d) The term 'employer' means a person, natural or legal, who either directly or through an intermediary, if any, gives out home work in pursuance of his or her business activity."

\section{POSITIVE IMPACT/ ADVANTAGES OF WORK FROM HOME}

Work from home is advantageous for the employees as well for the company due to the following:-

- Increases the productivity of employees: By working from home employees work more minutes per hour. They will take fewer breaks due to the ease of getting tea/coffee, lunch, toilet closer to them. They will take less sick leaves, time off etc. Employee turnover and absenteeism is reduced which in turn increases the profitability of the company as a whole.

- Increases the output per worker: This is attributable to quiet environment they are getting at home. They work quietly at home without any conflict with the colleagues thus increasing the output per worker and in turn the total output of the company.

- Reduction in cost: Working from home will reduce the cost of fuel for commuting from home to office by the employees. It also reduces the cost of maintaining infrastructure to be incurred by the company. Reduction in commutes means less miles travelled by vehicles which means less carbon emissions which leads to less pollution in environment which is a hottest issue recently.

- Saves a lot of time: This is attributable to the time spent in commuting from home to office. Some workers have to commute longer distance, that time can be utilized productively by working from home.

- Increases the morale and satisfaction of employees: Employees feel more satisfied by working from home by doing their work comfortably at a place they feel more suitable.

- Maintaining work life balance: It is easier for especially female employees to maintain their work-life balance by combining their care and responsibility towards their children and other family members. Women feel safer and secure by working at home.

- Reduce the attrition rate: Attrition rate means rate at which employees leave the organization over a specific period of time. By offering flexible working hours and working condition to employees according to their comfort the rate of employees leaving the organization will get reduced automatically.

- Facilitate the expansion of business: Work from home enables the company to expand the business at a given cost because capital cost in terms of infrastructure and space has 
reduced considerably by offering flexible working hours to employees and this will add to the profits of the company.

\section{NEGATIVE IMPACTS OR DISADVANTAGES OF WORK FROM HOME}

We cannot always say that work from home is advantageous. Every coin has two sides similarly work from home also has its limitations due to the following:

- It is not suitable for all types of companies: Work from home is mostly suitable for jobs like call centers, where administrative work is involved, which involve home made products, software companies, banks, technology firms etc. On the other hand it is not suitable for enterprises where public dealings are involved, where proper set up is required which cannot be provided at home.

- Teamwork cannot be promoted: By working individually at home, employees find it very difficult to cooperate with each other to complete a project as a team.

- Less Family time: When employees work in offices, they work for fixed hours (say from 9 am to $5 \mathrm{pm}$ ) but if they work from home they generally work for more minutes per hour which means less time to be spent with family.

- Difficult to measure performance: when employees work from home then it's very difficult to measure performance of employees (other than in terms of quantity of output).

- Reduced chances of promotion: When it is difficult to measure performance of employees then it is very difficult to promote the employees. Employees have approximately nil chances of promotion which in turn lowered their morale.

\section{WORK FROM HOME POLOICIES OF SOME OF THE RENOWNED COMPANIES}

1. Microsoft: In 2010 Microsoft formalized a policy of giving option to employees working to choose between office and home that suits them best. It has given three options to employees to select:

- Fixed scheduling: It is when employees are given the option to work from home for some working hours.

- Teleporting: Here the employees have to choose a schedule of days during which he will work only from home.

- Part-time: It is when employee works for only few hours.

2. IBM (India): In IBM nearly $40 \%$ employees work from home. The employees in IBM said that they have received Rs 15000 extra for working at home may be because companies has saved infrastructure and other related costs.

3. Flexi career (Chennai): As per this company, when companies take work from home as a means of work-life balance not as a means to attain business goals, then they start facing problems.

4. CISCO: Cisco advise its employees working from home to attend quarterly meetings to ensure cooperation between employees, Managers because employees work in isolation due to which they do not have external stimulus which is a critical factor to achieve business goals. Cisco has earned $\$ 277$ million as savings through work from home. Nearly $85 \%$ employees of Cisco work from home. 
5. Tata communications: Since a large part of our working population consist of young generations and women now also becoming part of working population, Tata communications devise new ways to provide them creative freedom and assumed responsibility. They allow their employees to work from home provided that this should be accompanied by proper training to employees and managers. Further employees should be engaged while devising such policies and modify it accordingly.

6. HP: approximately $25 \%$ employees in HP work from home. The company said where teamwork is involved then work from is a challenge. We cannot monitor whether the employees are actually working or not and they need to be self-disciplined and accountable when working from home.

7. ACCENTURE: This is the initial company in India to consider work from home as the best option for its employees to be comfortable in working. About $81 \%$ of their employees work from.

8. INFOSYS: Employees in Infosys are given an incentive to work 3.5 hours in a day in office and rest work can be completed at home. Now there is change in policy where employees can work for 9 days in a month from home

According to the above analysis, CISCO has the highest percentage of employees working from home followed by Accenture and IBM.s

\section{Graphical presentation of percentage of employees who opt work from home}

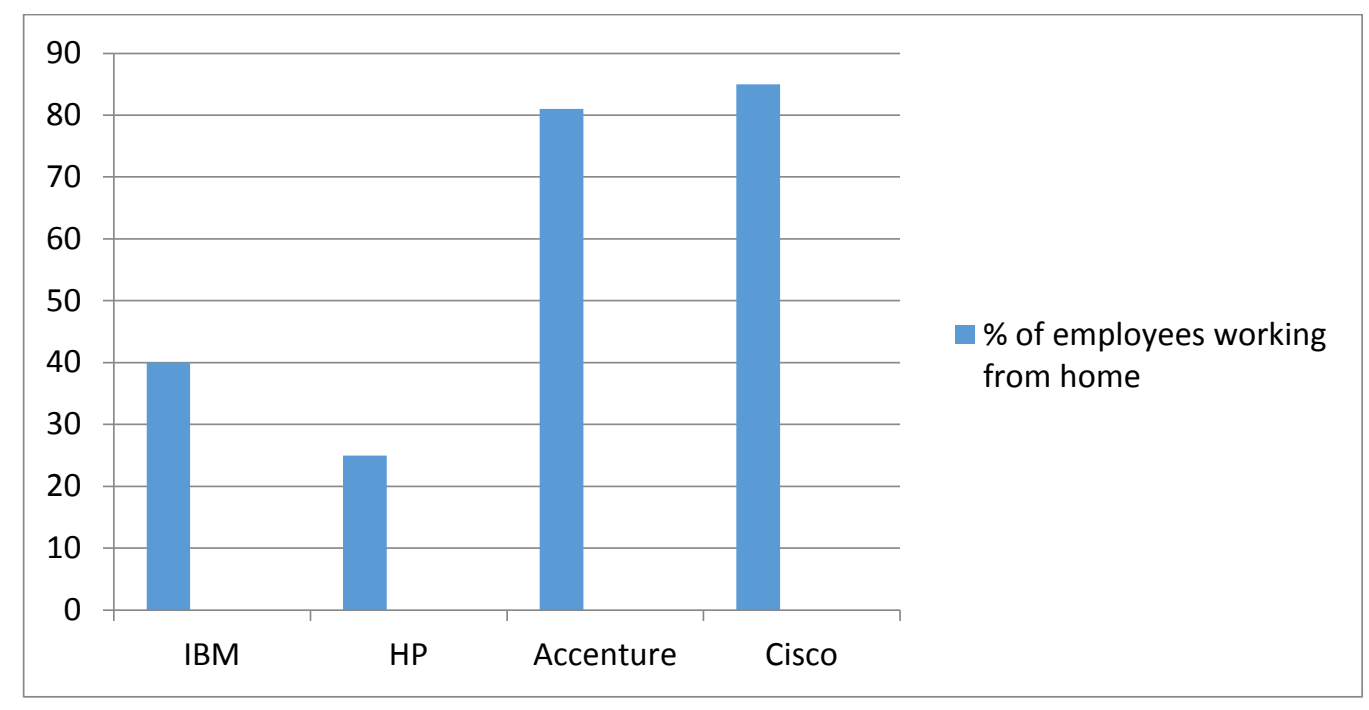

\section{RESEARCH METHODOLOGY}

Being an explanatory research, it is based on secondary data of journals, articles, newspaper and magazines. Considering the objectives of descriptive type research design is adopted to have more accuracy and rigorous analysis of research study. The accessible secondary data is extensively used for study. 


\section{LITERATURE REVIEW}

${ }^{1}$ Bloom, N., Liang, J., Robert, J., \& Jenny Ying, Z. (2014). DOES WORKING FROM HOME WORK? EVIDENCE FROM A CHINESE EXPERIMENT explained that:

Ctrip, there are over 16000 employees in a company of which call center employees are given an option to work either from home or office for nine months. They concluded that Work from home led to $13 \%$ rise in productivity of employees attributed to increasing minutes per hour and more calls per minutes. After the success of the experiment Ctrip extends this facility to the entire firm and surprisingly nearly half of the employees switched to work from and the benefits doubled.

Their experiments showed that because of work from home, attrition rate has reduced. They also explain how number of hours worked, call rate, attrition rate and capital cost affect the profits of firm from work from home.

According to the experiment, the effect of hours on work from home is ambiguous because the breaks taken at office are used for productive works but breaks taken at home are used for watching television and other unproductive purpose.

Effect of call rate on work from home is also ambiguous because it depends on support of supervisor in office. Certain tasks like writing paper can be best done at home and tasks requiring team work can be best performed in office.

${ }^{3}$ R.M.S., \& Sinha, S. (2011). Making Home-based Work Visible: A Review of Evidence from South Asia and concluded that:

- Although 10-15 years of research has been conducted to find a universally accepted definition of work from home but further research needs to be done for comparing definitions of different countries.

- Although micro level studies have been carried out using a combination of qualitative and quantitative methods.

- People working from home face many difficulties due to poverty, poor habitat, lack of facilities at home for doing official work.

- Workers specially women face difficulties due to gender norms constraints although the condition is not that pity now a days but further research needs to be done to find out ways in which gender social norms change over time.

${ }^{4}$ Srivastava, K., Sethumadhavan, A., Raghupathy,, H., Agarwal, S., \& Rawat, S.R. (2015). To Study the Indian Perspective on the Concept of Work from Home. came up with the following conclusion:

- Working from home is clearly favored by IT sector employees because they are very similar to their western counterparts in balancing advantages and disadvantages of telecommuting.

- They referred it as a green concept because it results in lesser pollution and cleaner environment due to less travelling. 
- They are able to balance their professional and personal lives and save a lot of time on account of less travelling and informal talks with colleagues.

- It results in lack of communication and meetings with colleagues, managers, workers which leads to less coordination.

\section{CONCLUSIONS AND RECOMMENDATIONS}

As a writer of this paper I would like to conclude that although not much evidence has been there regarding success or failure of work from home but according to my analysis I would like to say that work from home is successful mostly in developed nations like U.S.A, China etc. In India it is a new concept and will take time to be successful. Many MNCs now start giving this facility but a lot needs to be done in this regard. Domestic Companies giving this facility are negligible in number. I want to recommend that companies who are not giving this facility must start giving flexible working hours to their employees at least twice or thrice a week if not the whole week or few days a month in order to retain the employees for longer and to boost their morale so that employees feel satisfactory working in a company. It will also contribute to the economic development of a country because of increase in output per worker and hence the total output has increased which is nothing but GDP of a country. Also by offering this facility more and more females will be willing to work which will improve the literacy rate of a country and thus the economy will move ahead towards the path of transition from developing to developed nation.

\section{REFERENCES}

[1] Bloom, N., Liang, J., Robert, J., \& Jenny Ying, Z. (2014). DOES WORKING FROM HOME WORK? EVIDENCE FROM A CHINESE EXPERIMENT. The Quarterly Journal of Economics (2015),

[2] Beauregard, A., Basile, K., \& Canonico, E. (2013). HOME IS WHERE THE WORK IS: A new study of homeworking in Acas - and beyond. Acas research publications,

[3] , R.M.S., \& Sinha, S. (2011). Making Home-based Work Visible: A Review of Evidence from South Asia. WIEGO Urban Policies Research Report Series,

[4] Srivastava, K., Sethumadhavan, A., Raghupathy,, H., Agarwal, S., \& Rawat, S.R. (2015). To Study the Indian Perspective on the Concept of Work from Home. Indian Journal of Science and Technology,

[5] www.wikipedia.com

[6] http://surejob.in/companies-in-india-that-allow-working-from-home.html

[7] http://timesofindia.indiatimes.com/tech/slideshow/workfromhome/16-IT-cos-offeringwork-from-home-option/itslideshowviewall/11794339.cms 